ORIGINAL ARTICLE

\title{
Acid suppression does not change respiratory symptoms in children with asthma and gastro-oesophageal reflux disease
}

\author{
K Størdal, G B Johannesdottir, B S Bentsen, P K Knudsen, K C L Carlsen, O Closs, M Handeland, \\ H K Holm, L Sandvik
}

Arch Dis Child 2005;90:956-960. doi: 10.1136/adc.2004.068890

See end of article for authors' affiliations

Correspondence to: Dr K Størdal, Dept of Paediatrics, Østfold Central Hospital, 1602 Frederikstad, Norway; ketil.stoerdal@c2i.net

Accepted 14 April 2005

\begin{abstract}
Background: Epidemiological studies have shown an association between gastro-oesophageal reflux disease (GORD) and asthma, and oesophageal acid perfusion may cause bronchial constriction. However, no causative relation has been proven.

Aim: To assess whether acid suppression would lead to reduced asthma symptoms in children with concomitant asthma and GORD.

Methods: Thirty eight children (mean age 10.8 years, range 7.2-16.8; 29 males) with asthma and a reflux index $\geqslant 5.0$ assessed by 24 hour oesophageal $\mathrm{pH}$ monitoring were randomised to 12 weeks of treatment with omeprazole $20 \mathrm{mg}$ daily or placebo. The groups were similar in age, gender, mean reflux index, and asthma severity. Primary endpoints were asthma symptoms (daytime wheeze, symptoms at night, in the morning, and during exercise) and quality of life (PAQLQ). Secondary endpoints were changes in lung function and the use of short acting bronchodilators. At the end of the study a repeated $\mathrm{pH}$ study was performed to confirm the efficacy of acid suppression.

Results: The change in total symptom score did not differ significantly between the omeprazole and the placebo group, and decreased by $1.28(95 \% \mathrm{Cl}-0.1$ to 2.65$)$ and $1.28(95 \% \mathrm{Cl}-0.72$ to 3.27$)$ respectively. The PAQLQ score increased by $0.62(95 \% \mathrm{Cl} 0.29$ to 0.95$)$ in the omeprazole group compared to $0.50(95 \% \mathrm{Cl} 0.29$ to 0.70$)$ in the placebo group. Change in lung function and use of short acting bronchodilators were similar in the groups. The acid suppression was adequate (reflux index $<5.0$ ) under omeprazole treatment.

Conclusion: Omeprazole treatment did not improve asthma symptoms or lung function in children with asthma and GORD.
\end{abstract}

$\mathrm{T}$ he association between asthma and gastro-oesophageal reflux disease (GORD) has been debated for decades, ${ }^{12}$ and epidemiological studies have repeatedly shown this association in adults and children. ${ }^{3-6}$ A causative relation is still unclear, even though acid perfusion of the lower oesophagus may induce bronchoconstriction in animal models ${ }^{7}$ and in humans, ${ }^{89}$ probably mediated through a vagal reflex. ${ }^{9}$ Microaspiration is an alternative pathophysiological mechanism, as shown by scintigraphic studies ${ }^{10}$ and analyses of bronchoalveolar lavage fluid. ${ }^{11}{ }^{12}$

A limited number of studies reviewed in a recent Cochrane report ${ }^{13}$ have evaluated the effect of GORD treatment, with conflicting results with respect to asthma symptoms and lung function. One single randomised controlled study in children indicated a modest effect of ranitidine on nocturnal asthma symptoms. ${ }^{14}$ However, modern GORD treatment with proton pump inhibitors in children with asthma has not yet been studied. Proton pump inhibitors are superior to former treatment as regards GORD and the healing of oesophagitis, with improved control of acid secretion. ${ }^{15}{ }^{16}$ Thus, we aimed to assess possible efficacy on asthma outcome of omeprazole in children with asthma and confirmed GORD.

\section{METHODS}

\section{Patients}

Children between 7 and 16 years of age with doctors diagnosed asthma were asked at their regular outpatient controls from June 2001 to December 2003 to complete a seven point questionnaire ${ }^{17}$ addressing gastrointestinal symptoms associated with GORD (box 1). Those with at least one symptom present were, after informed consent, offered a 24 hour $\mathrm{pH}$ monitoring.

A reflux index $(\mathrm{RI}=$ percentage of total recording time with $\mathrm{pH}<4.00$ ) of 5.0 or more was considered abnormal. ${ }^{18} 19$ Inclusion criteria were an abnormal $\mathrm{pH}$ study and doctors diagnosed asthma with at least two episodes of asthma symptoms requiring medication over the last six months. Patients with previously known or treated GORD were excluded.

\section{Methods and treatment}

The pH study was performed using a Synectics Digitrapper MKIII (Stockholm, Sweden) connected to an antimony electrode introduced transnasally and placed over the third vertebral body above the diaphragm; the position was confirmed by fluoroscopy. After completion of a 24 hour monitoring session, the readings were downloaded to a computer using dedicated software (Medtronic, Copenhagen, Denmark) for analysis and storage.

After eligibility was confirmed, treatment allocation was performed using sequentially numbered containers from the manufacturer (AstraZeneca, Mölndal, Sweden). The patients were randomly allocated to receive either omeprazole $20 \mathrm{mg}$ daily or placebo for 12 weeks. The patients, the caregivers, and the study personnel were blinded to the treatment for the duration of the study.

After a two week run-in period as well as at the end of treatment, two separate questionnaires were completed and 
Box 1: Symptoms from the childhood gastrooesophageal reflux questionnaire during the past week

- Did you throw up?

- Did you feel like throwing up or nauseous?

- Did you have a burning or painful feeling in the middle of the chest?

- Did you have stomach ache?

- Did you have stomach ache above the belly button?

- Did you have a sour taste, like the taste of throw up, in the mouth?

- Did it hurt to swallow food or drink?

applied as primary endpoints. The first questionnaire assessed asthma symptoms over the past four weeks (table 1), and the second was the validated Pediatric Asthma Quality of Life Questionnaire (PAQLQ). ${ }^{20}$

Lung function was monitored by spirometry (Jaeger, Germany) according to accepted standards ${ }^{21}$ at weeks 0, 6, and 12: forced expiratory volume in 1 second expressed as percent of vital capacity $\left(\mathrm{FEV}_{1 \%}\right)$ and forced expiratory flow at $25-75 \%$ of lung volume $\left(\mathrm{FEF}_{25-75}\right)$ were registered. $\mathrm{FEF}_{25-75}$ was chosen to detect changes in resistance in the smaller airways. $^{22}$ The use of rescue medication with short acting $\beta_{2}$ agonists during the past two weeks was recorded at weeks 0 , 6 , and 12 . Other asthma medication was not changed unless required due to exacerbations during the study period. If changes in asthma medication occurred, this was recorded to make necessary corrections in the analyses.

Skin prick tests and specific IgE against common airway allergens (household animals, pollen, house dust mite, cladosporium) and food antigens (egg, milk, soy, fish, peanuts) were performed if this had not been done during the last three years. Total IgE in full blood samples together with cell counts were measured at inclusion, and eosinophilic cationic protein (ECP) was measured at weeks 0 and 12 . Patients with total IgE above the age specific cut-off level, increased specific IgE, and/or positive skin prick test were classified as atopic asthmatics.

To confirm that adequate acid suppression (reflux index $<5.0$ ) had been achieved, the consenting participants performed a repeated $\mathrm{pH}$ study before the treatment ended.

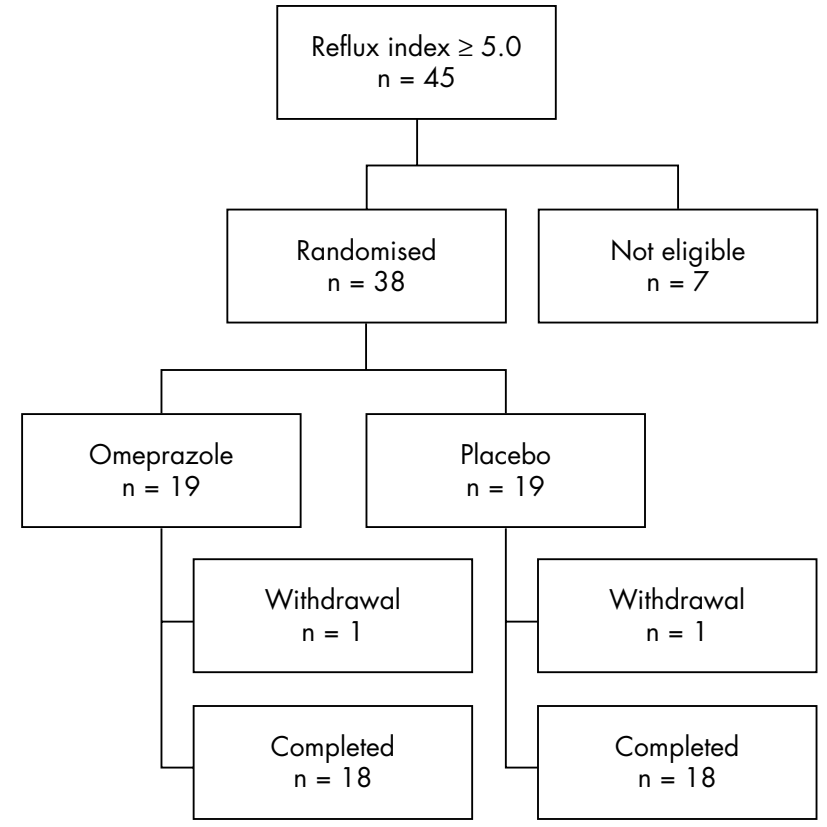

Figure 1 Flow of patients through the study.

\section{Statistics and sample size}

All changes were expressed as changes from baseline. The treatment and placebo group were compared using two sided $t$ tests for independent samples with a $5 \%$ significance level when requirements for a normal distribution could be fulfilled. The Mann-Whitney U test was applied when criteria for normal distribution could not be met. Subgroup analyses were performed for non-atopic and atopic individuals, for those with more severe reflux (RI >10.0), and for those with more severe asthma symptoms at inclusion.

To obtain an $80 \%$ chance of detecting a clinically relevant difference between the two groups of one standard deviation in the change in symptom score or PAQLQ, 16 patients were needed in each group. Thus, we aimed to enrol 36 patients to allow for an estimated $10 \%$ drop-out rate.

\section{Ethics}

The study was approved by the Regional Committee for Medical Research Ethics. Written informed consent was obtained from all participants and parents.

Table 1 Scoring for asthma symptoms during the past four weeks (at weeks 0, 6, and 12)

\begin{tabular}{|c|c|c|}
\hline Question & Alternative & Points \\
\hline How often have you experienced wheezing or tightness in the chest the past month? & $\begin{array}{l}\text { 4-7 days a week } \\
1-3 \text { days a week } \\
\text { Less than once a week } \\
\text { Not at all }\end{array}$ & $\begin{array}{l}3 \\
2 \\
1 \\
0\end{array}$ \\
\hline How often did coughing or tightness in the chest wake you up during the past month? & $\begin{array}{l}4-7 \text { nights a week } \\
1-3 \text { nights a week } \\
\text { Less than once a week } \\
\text { Not at all }\end{array}$ & $\begin{array}{l}3 \\
2 \\
1 \\
0\end{array}$ \\
\hline $\begin{array}{l}\text { How often during the past month did you have asthma symptoms when waking up } \\
\text { in the morning? }\end{array}$ & $\begin{array}{l}4-7 \text { days a week } \\
1-3 \text { days a week } \\
\text { Less than once a week } \\
\text { Not at all }\end{array}$ & $\begin{array}{l}3 \\
2 \\
1 \\
0\end{array}$ \\
\hline $\begin{array}{l}\text { How often have you been troubled in physical activities by coughing, wheezing, } \\
\text { or tightness in the chest the past month? }\end{array}$ & $\begin{array}{l}4-7 \text { days a week } \\
1-3 \text { days a week } \\
\text { Less than once a week } \\
\text { Not at all }\end{array}$ & $\begin{array}{l}3 \\
2 \\
1 \\
0\end{array}$ \\
\hline
\end{tabular}


Table 2 Group characteristics at inclusion for 7-16 year old children with asthma treated with omeprazole or placebo for GORD

\begin{tabular}{lll} 
& & \\
& $\begin{array}{l}\text { Omeprazole } \\
(\mathbf{n}=19)\end{array}$ & $\begin{array}{l}\text { Placebo } \\
\text { (n= 19) }\end{array}$ \\
\hline Age: mean (median) & $10.2(9.2)$ & $11.3(11.0)$ \\
Gender (male/female) & $15 / 4$ & $14 / 5$ \\
Reflux index, mean (\%, SD) & $8.8(4.0)$ & $9.7(5.1)$ \\
Not completed (n) & 1 & 1 \\
Patients with reflux index >10\% (n) & 5 & 6 \\
Atopic/non-atopic individuals & $13 / 6$ & $13 / 6$ \\
Asthma symptom score: mean (SD) & $5.53(3.26)$ & $5.95(2.92)$ \\
PAQLQ*: mean (SD) & $5.49(0.79)$ & $5.32(0.95)$ \\
GINA classification of asthma severity (step 1/2/3/4)† & $4 / 8 / 7 / 0$ & $3 / 6 / 10 / 0$ \\
Use of short acting bronchodilators (doses past two weeks): & $11.00(17.23)$ & $8.28(8.52)$ \\
mean (SD) & 17 & 17 \\
Patients on daily inhaled steroids (n) & 10 & 12 \\
Patients on daily long acting bronchodilators (n) & $88.6(9.5)$ & $86.9(7.8)$ \\
FEV ${ }_{1 \% \text { : mean (SD) }}$ & & \\
\hline *PAQLQ, Pediatric Asthma Quality of Life Questionnaire. & & \\
†GINA, Global Initiative on Asthma. ${ }^{23}$ & &
\end{tabular}

\section{RESULTS}

Of the initial 165 children with asthma and symptoms of GORD who consented to a pH study, $45(28 \%)$ had an RI $\geqslant 5$.0. Three were not eligible for randomisation because of paucity of asthma symptoms as described previously, two withdrew before randomisation, and two had incomplete $\mathrm{pH}$ studies.

The remaining 38 children were randomly allocated to omeprazole or placebo treatment. The groups were similar in age and gender distribution, mean reflux index, and asthma severity (table 2 ). One in each group withdrew because of suspected side effects (headache, worsened asthma symptoms), leaving 18 in each group for final analysis (fig l).

The change in mean symptom score and PAQLQ from baseline did not differ significantly between the omeprazole and the placebo group (table 3). Symptoms in all four subscores listed in table 2 improved, but with no significant differences between the groups (data not shown). Changes in spirometry values, the use of short acting bronchodilators, and ECP were similar in the two groups (table 3 ).

The 11 patients with RI $>10.0$ were analysed separately, and an improvement in PAQLQ of 0.96 (95\% CI -1.6 to 3.6 ) in the omeprazole and of $0.34(95 \%$ CI -0.14 to 0.82$)$ in the placebo group was found $(p=0.24)$. Selecting the more symptomatic asthma patients (baseline PAQLQ $<5.0$, five in each group) showed an improvement in PAQLQ of 0.96 (95\% $\mathrm{CI}-0.08$ to 2.00$)$ in the omeprazole group and of $0.50(95 \%$ CI 0.11 to 0.89$)$ in the placebo group $(p=0.29)$.

Analysing atopic $(n=25)$ and non-atopic $(n=11)$ children separately showed similar baseline reflux indexes in the two groups $(9.3 \% v 9.4 \%)$. In the atopic children PAQLQ improved by 0.55 ( $95 \%$ CI 0.24 to 0.85$)$ in the omeprazole group compared to 0.56 (95\% CI 0.29 to 0.84 ) in the placebo group $(\mathrm{p}=0.94)$. In the non-atopic asthma patients PAQLQ improved by 0.76 (95\% CI -0.40 to 1.94 ) in the omeprazole and by 0.32 (95\% CI -0.02 to 0.66$)$ in the placebo group $(\mathrm{p}=0.34)$.

The acid suppression by omeprazole was adequate (RI $<5.0$ ) at a repeated $\mathrm{pH}$ study in seven of the eight patients consenting to a second $\mathrm{pH}$ study, with a mean reduction in RI of $4.9(2.7-7.1, p=0.001)$. In the placebo group the second $\mathrm{pH}$ study was abnormal in five of seven patients.

\section{DISCUSSION}

The present study did not show any effect of omeprazole treatment on asthma symptoms or quality of life in children with concomitant asthma and GORD. Nor were there any significant effects of oesophageal acid suppression on lung function and the use of $\beta_{2}$ agonists.

Studies on omeprazole in adults with asthma have in accordance with our study failed to prove any effect on asthma outcome, ${ }^{24-26}$ though some smaller studies report improvement in peak expiratory flow or asthma symptoms. ${ }^{27-29}$ In children with asthma only one uncontrolled study has been published, reporting on a variety of treatments including proton pump inhibitors. ${ }^{30}$

Most of the previous studies on acid suppression in asthmatics with GORD have not included measurements of the efficacy of GORD treatment, and thus cannot reliably answer the more complicated question whether reduced oesophageal acid exposure improves lung symptoms. We intended to perform a second $\mathrm{pH}$ monitoring in all participants to ensure that adequate acid suppression was achieved. Less than half consented to a second study; thus some of the treated children may have received inadequate treatment for their acid reflux. The dosage of $20 \mathrm{mg}$ omeprazole corresponds to $0.25-1 \mathrm{mg} / \mathrm{kg}$, sufficient for the majority of children with GORD. ${ }^{31}$ A longer duration of

Table 3 Outcome measures in children with asthma and GORD treated with omeprazole and placebo

\begin{tabular}{llll}
\hline & Omeprazole $(\mathbf{n}=\mathbf{1 8})$ & Placebo $(\mathbf{n}=18)$ & p value \\
\hline Symptom score & $-1.28(-2.65$ to 0.1$)$ & $-1.28(-3.27$ to 0.72$)$ & 1.00 \\
PAQLQ & $-0.62(-0.29$ to -0.95$)$ & $-0.50(-0.29$ to -0.70$)$ & 0.51 \\
FEV $1 \%$ (mean, median) & $-1.38(0.33)$ & $-2.01(-0.50)$ & 0.77 \\
FEF $_{25-75}$ (mean, median) & $-0.07(-0.05)$ & $0.04(0.05)$ & 0.12 \\
Rescue medication (mean, median) & $-1.9(0.0)$ & $-1.9(0.5)$ & 0.89 \\
ECP baseline & $25.9(14.3 .37 .5)$ & $20.2(12.7$ to 27.7$)$ & \\
ECP change & $1.27(-5.5$ to 8.1$)$ & $1.39(-4.3$ to 7.1$)$ & 0.98 \\
\hline
\end{tabular}

Values expressed as changes from baseline (week 0) to end of treatment (week 12) with $95 \%$ confidence intervals for mean $( \pm 1.96$ SEM) unless otherwise stated. 


\section{What is already known on this topic}

- Epidemiological studies have repeatedly shown an association between GORD and asthma

- Acid perfusion of the oesophagus may induce bronchoconstriction

treatment may be required to achieve the potential effect on asthma than in GORD without respiratory symptoms. ${ }^{32}$ Considering these limitations, we would have expected at least a trend towards a treatment effect in our study if acid suppression was of clinical importance in asthmatic children with GORD.

Our study was relatively small, but adequately powered to detect significant differences in major efficacy outcomes. The lack of differences in outcome in subgroup analysis in children with atopic versus non-atopic asthma may be due to small sample sizes. Children with more severe reflux disease (RI $>10.0 \%$ ) may have a treatment effect as suggested by the trend in our study, but the sample is too small to draw firm conclusions.

Studies on proton pump inhibitors using impedance measurements have failed to prove any effect on non-acidic reflux. $^{33}$ The differentiation between acid and non-acidic reflux regarding respiratory symptoms may be important. The data showing no effect of acid suppression on asthma should therefore not be generalised into treatment of GORD in general; as suggested by some studies, ${ }^{34}{ }^{35}$ surgical treatment may have an effect.

Most children with GORD have neither histological nor macroscopic signs of oesophagitis, ${ }^{36}$ and the risk of oesophagitis in individuals with GORD increases with age. ${ }^{37}$ One of the proposed mechanisms for acid exposure to the oesophageal mucosa and bronchoconstriction may be restricted to those having an oesophagitis which exposes the afferent vagal nerve to acid. Our study population did not undergo endoscopy, and thus this question cannot be addressed.

Our study included children and adolescents from 7 years of age; studying younger children may yield different findings. The main problem in the younger age group is the definition of asthma, with a limited access to lung function tests. Children with respiratory symptoms from GORD may be wrongly diagnosed with asthma on a symptom basis, and this has to be taken into account when studying asthma and GORD in young children.

A subgroup of patients with a temporal relation between gastrointestinal and respiratory symptoms has been suggested to benefit from acid suppression. ${ }^{13}$ However, only a few of the patients in the present study fulfil this criterion. The children studied were mainly well treated asthmatics, as shown in table 2. A treatment effect may have been found if only children with severe asthma had been included. However, the children included in the present study reflect the asthma population, with most of the children with mild or moderate persistent asthma, and relatively well controlled asthma on daily inhaled steroids. Thus improvement in asthma outcome may be difficult to obtain and a possible ceiling effect needs consideration, as suggested by the analysis in the subgroup with most severe asthma and lowest PAQLQ at baseline.

\section{Conclusion}

The present study could not show any effect of a 12 week treatment with a proton pump inhibitor on asthma symptoms, quality of life, or lung function in children with asthma
What this study adds

- Acid suppression in children with asthma and GORD did not improve asthma symptoms

- Subgroups with the more severe forms of asthma and GORD may benefit from acid suppression of asthma symptoms

and GORD. A causal relation between acid reflux and asthma remains unproven.

\section{ACKNOWLEDGEMENTS}

We acknowledge: Aase Urkedal, Laila Aaserud, Jan Ivar Holme, Frode Njå, Tore Røed, and Aud Gaasemyr for recruiting patients to the study; study nurses Ingunn Malmberg and Kari Torp Hansen; Jarle Rugtveit, Knut Dahl-Jørgensen, Knut Olav Bøe; and Morten Pettersen for valuable comments to the study protocol; and the Norwegian Foundation for Health and Rehabilitation and AstraZeneca for financial support.

\section{Authors' affiliations}

K Størdal, Dept of Paediatrics, Østfold County Hospital, 1602 Fredrikstad, Norway

G B Johannesdottir, B S Bentsen, P K Knudsen, K C L Carlsen, Dept of Paediatrics, Ullevaal University Hospital, 0407 Oslo, Norway O Closs, Dept of Paediatrics, Ahus University Hospital, 1474 Nordbyhagen, Norway

M Handeland, Dept of Paediatrics, Vestfold Hospital, 3103 Tønsberg, Norway

H K Holm, Dept of Paediatrics, Oppland County Hospital, 2629

Lillehammer, Norway

L Sandvik, Center for Clinical Research, Ullevaal University Hospital, 0407 Oslo, Norway

Competing interests: KS has been reimbursed from AstraZeneca for attending two conferences, and KS and BSB have received fees from AstraZeneca for speaking

\section{REFERENCES}

1 Bray G. Recent advances in the treatment of asthma and hay fever. Practitioner 1934;133:368-79.

2 Kennedy J. "Silent" gastroesophageal reflux: an important but little known cause of pulmonary complications. Dis Chest 1962;42:42-5

3 El Serag HB, Gilger M, Carter J, et al. Childhood GERD is a risk factor for GERD in adolescents and young adults. Am J Gastroenterol 2004;99:806-12

4 Gislason T, Janson C, Vermeire P, et al. Respiratory symptoms and nocturnal gastroesophageal reflux: a population-based study of young adults in three European countries. Chest 2002;121:158-63.

5 Harding SM, Guzzo MR, Richter JE. The prevalence of gastroesophageal reflux in asthma patients without reflux symptoms. Am J Respir Crit Care Med 2000; 162:34-9.

6 Harding SM. Acid reflux and asthma. Curr Opin Pulm Med 2003;9:42-5.

7 Tuchman DN, Boyle JT, Pack Al, et al. Comparison of airway responses following tracheal or esophageal acidification in the cat. Gastroenterology 1984;87:872-81

8 Davis RS, Larsen GL, Grunstein MM. Respiratory response to intraesophageal acid infusion in asthmatic children during sleep. J Allergy Clin Immunol 1983;72:393-8.

9 Schan CA, Harding SM, Haile JM, et al. Gastroesophageal reflux-induced bronchoconstriction. An intraesophageal acid infusion study using state-ofthe-art technology. Chest 1994; 106:731-7.

10 Ruth M, Carlsson S, Mansson I, et al. Scintigraphic detection of gastropulmonary aspiration in patients with respiratory disorders. Clin Physiol 1993;13:19-33.

11 Krishnan U, Mitchell JD, Messina I, et al. Assay of tracheal pepsin as a marker of reflux aspiration. J Pediatr Gastroenterol Nutr 2002;35:303-8.

12 Sacco O, Fregonese B, Silvestri $M$, et al. Bronchoalveolar lavage and esophageal $\mathrm{pH}$ monitoring data in children with "difficult to treat" respiratory symptoms. Pediatr Pulmonol 2000;30:313-19.

13 Gibson PG, Henry RL, Coughlan JL. Gastro-oesophageal reflux treatment for asthma in adults and children. Cochrane Database Syst Rev 2003;(2):CD001496

14 Gustafsson PM, Kjellman NI, Tibbling L. A trial of ranitidine in asthmatic children and adolescents with or without pathological gastro-oesophageal reflux. Eur Respir J 1992;5:201-6. 
15 Jones R, Bytzer P. Review article: acid suppression in the management of gastro-oesophageal reflux disease - an appraisal of treatment options in primary care. Aliment Pharmacol Ther 2001;15:765-72.

16 Tytgat GN. Review article: management of mild and severe gastrooesophageal reflux disease. Aliment Pharmacol Ther 2003;17(suppl 2):52-6.

17 Nelson SP, Chen EH, Syniar GM, et al. Prevalence of symptoms of gastroesophageal reflux during childhood: a pediatric practice-based survey. Pediatric Practice Research Group. Arch Pediatr Adolesc Med 2000;154:150-4.

18 Johnson LF, DeMeester TR. Twenty-four-hour $\mathrm{pH}$ monitoring of the distal esophagus. A quantitative measure of gastroesophageal reflux. Am J Gastroenterol 1974;62:325-32.

19 Sondheimer JM, Haase GM. Simultaneous $\mathrm{pH}$ recordings from multiple esophageal sites in children with and without distal gastroesophageal reflux. J Pediatr Gastroenterol Nutr 1988;7:46-51.

20 Juniper EF, Guyatt GH, Feeny DH, et al. Measuring quality of life in children with asthma. Qual Life Res 1996;5:35-46.

21 American Thoracic Society. Standardization of spirometry, 1994 update. Am J Respir Crit Care Med 1995;152:1 107-36.

22 Lebecque $P$, Kiakulanda P, Coates AL. Spirometry in the asthmatic child: is FEF25-75 a more sensitive test than FEVI/FVC? Pediatr Pulmonol 1993;16:19-22.

23 Von Mutius E. Presentation of new GINA guidelines for paediatrics. The Global Initiative on Asthma. Clin Exp Allergy 2000;30(suppl 1):6-10.

24 Boeree MJ, Peters FT, Postma DS, et al. No effects of high-dose omeprazole in patients with severe airway hyperresponsiveness and (a)symptomatic gastrooesophageal reflux. Eur Respir J 1998;11:1070-4.

25 Ford GA, Oliver PS, Prior JS, et al. Omeprazole in the treatment of asthmatics with nocturnal symptoms and gastro-oesophageal reflux: a placebo-controlled cross-over study. Postgrad Med J 1994;70:350-4.

26 Kiljander TO, Salomaa ER, Hietanen EK, et al. Gastroesophageal reflux in asthmatics: a double-blind, placebo-controlled crossover study with omeprazole. Chest 1999;116:1257-64.
27 Teichtahl H, Kronborg IJ, Yeomans ND, et al. Adult asthma and gastrooesophageal reflux: the effects of omeprazole therapy on asthma. Aust N Z J Med 1996;26:671-6.

28 Levin TR, Sperling RM, McQuaid KR. Omeprazole improves peak expiratory flow rate and quality of life in asthmatics with gastroesophageal reflux. Am J Gastroenterol 1998;93:1060-3.

29 Meier JH, McNally PR, Punja M, et al. Does omeprazole (Prilosec) improve respiratory function in asthmatics with gastroesophageal reflux? A doubleblind, placebo-controlled crossover study. Dig Dis Sci 1994;39:2127-33.

30 Khoshoo V, Le T, Haydel RM Jr, et al. Role of gastroesophageal reflux in older children with persistent asthma. Chest 2003;123:1008-13.

31 Gibbons TE, Gold BD. The use of proton pump inhibitors in children: a comprehensive review. Paediatr Drugs 2003;5:25-40.

32 Orenstein SR. Management of GER in childhood asthma. Pediatr Pulmonol Suppl 1995;11:57-8.

33 Vela MF, Camacho-Lobato L, Srinivasan R, et al. Simultaneous intraesophageal impedance and $\mathrm{pH}$ measurement of acid and nonacid gastroesophageal reflux: effect of omeprazole. Gastroenterology 2001; 120:1599-606.

34 Kiljander TO, Salomaa ER, Hietanen EK, et al. Gastroesophageal reflux and bronchial responsiveness: correlation and the effect of fundoplication. Respiration 2002;69:434-9.

35 Sontag SJ, O'Connell S, Khandelwal S, et al. Asthmatics with gastroesophageal reflux: long term results of a randomized trial of medical and surgical antireflux therapies. Am J Gastroenterol 2003;98:987-99.

36 Vandenplas $Y$. Reflux esophagitis in infants and children: a report from the Working Group on Gastro-Oesophageal Reflux Disease of the European Society of Paediatric Gastroenterology and Nutrition. J Pediatr Gastroenterol Nutr 1994; 18:413-22.

37 Voutilainen M, Sipponen P, Mecklin JP, et al. Gastroesophageal reflux disease: prevalence, clinical, endoscopic and histopathological findings in 1,128 consecutive patients referred for endoscopy due to dyspeptic and reflux symptoms. Digestion 2000;61:6-13. 